\title{
Natural products as inhibitors of COVID-19 main protease - A virtual screening by molecular docking
}

\author{
Marzieh omrani \\ Shahid Beheshti University \\ Mohammad Bayati \\ Shahid Beheshti University \\ Parvaneh Mehrbod ( $\nabla$ mehrbode@yahoo.com) \\ Pasteur Institute of Iran https://orcid.org/0000-0002-8391-9228 \\ Samad Nejad-Ebrahimi \\ Shahid Beheshti University
}

\section{Research}

Keywords: HTVS, Induced-fit docking, Molecular modeling, SARS-COVID-19

Posted Date: August 19th, 2020

DOI: https://doi.org/10.21203/rs.3.rs-57351/v1

License: (c) (i) This work is licensed under a Creative Commons Attribution 4.0 International License. Read Full License

Version of Record: A version of this preprint was published at Pharmaceutical Sciences on March 3rd, 2021. See the published version at https://doi.org/10.34172/PS.2021.11. 


\section{Abstract}

Background: The novel coronavirus (2019-nCoV) causes a severe respiratory illness that was unknown in the human before. Its alarmingly quick transmission to many countries across the world resulted in a worldwide health emergency. It has caused a notable percentage of morbidity and mortality. Therefore, an imminent need for drugs to combat this disease has been increased. Global collaborative efforts from scientists are underway to find a therapy to treat infections and reduce death cases. Herbal medicines and purified natural products have been reported to have antiviral activity against Coronaviruses (CoVs).

Methods: In this study, a High Throughput Virtual Screening (HTVS) protocol was used as a fast method on the discovery of novel drug candidates as the COVID-19 main protease inhibitors. Over 180,000 natural product-based compounds were obtained from the ZINC database and virtually screened against the COVID-19 main protease. In this study, the Glide docking program was applied for high throughput virtual screening. Extra precision (XP) and in a combination of Prime module, induced-fit docking (IFD) approach was also used. Additionally, the ADME properties of all compounds were analyzed, and the final selection was carried out based on the Lipinski rule of five.

Results: The nineteen compounds were selected and introduced as new potential inhibitors. The compound ZINC08765174 (1-[3-(1 H-indol-3yl) propanoyl]-N-(4-phenylbutan-2-yl)piperidine-3-carboxamide) showed a strong binding affinity $(-11.5 \mathrm{kcal} / \mathrm{mol})$ to the crucial residues of COVID-19 main protease comparing to peramivir (-9.8 kcal/mol) as a positive control.

Conclusions: The excellent ADME properties proposed the opportunity of this compound to be a promising candidate for the treatment of COVID-19.

\section{Background}

Unusual viral pneumonia caused by COVID-19, known as the 2019 novel coronavirus (2019-nCoV), broke out in December 2019 in Wuhan, Hubei Province, China [1]. The World Health Organization (WHO) has declared it as a global public health emergency. The 2019-nCoV is spreading all over the world. The novel coronavirus (2019-nCoV) causes a severe respiratory illness that was unknown in the human before. Its alarmingly quick transmission to many countries around the globe resulted in a worldwide health emergency. Because of the high rate of spreading of COVID-19 all over the globe WHO recognized it as a pandemic on the $11^{\text {th }}$ of March 2020. It has caused a notable percentage of morbidity and mortality. Thus far, the total number of confirmed COVID-19 infections in the world is more than two million, and the number of deaths has been reached 140,000 individuals [2].

Coronaviruses (CoVs) belong to Coronaviridae, which are enveloped viruses with non-segmented single-stranded positive-sense RNA. They infect many species of animals (livestock, mouse, bat, birds, and many other wild animals) and humans and cause respiratory, enteric, hepatic, and neurologic diseases [3]. The typical genome of CoV includes 5'-cap, 5'-untranslated region (UTR), open reading frames, 3'-UTR, and 3'-poly (A) tail. The first two-thirds of the genome encode the nonstructural proteins that form the replicase complex. The last third of the genome encodes primarily structural proteins [4]. Two CoVs, including Severe Acute Respiratory Syndrome (SARS) and the Middle East Respiratory Syndrome (MERS) can result in infection and fatal respiratory disease in humans[5, 6].

The scientific community has begun an effort to find some candidate drugs with antiviral properties to reduce fatality caused by COVID-19 [7, 8]. Herbal medicines and purified natural products play an essential role in inhibiting and complementary therapies by modulating the immunomodulatory system of infected and uninfected persons. Antiviral effects of some natural products against some critical viral pathogens including coronavirus ( $\mathrm{CoV})$ has been reported $[9,10]$. Saikosaponins are a group of oleanane derivatives that have been isolated from some medicinal plants such as Heteromorpha spp [11]. Saikosaponins were found to possess antiviral activity on HCoV-229E which inhibited HCoV-229E viral infection by inhibiting viral attachment to cells, blocking viral penetration into cells, and interfering with the early stage of viral replication [12]. Myricetin [13] and scultellarein [14] are naturally occurring flavonoids that can be isolated from some plants such as tea, berries, fruits, vegetables and medicinal herbs [15]. Flavonoids like myricetin and scutellarein have been identified as novel chemical inhibitors of the SARS coronavirus helicase [16]. In 2017, the inhibitory activity of polyphenols derived from Broussonetia papyrifera against CoV cysteine proteases was assessed. All isolated polyphenols including broussochalconeA, 4-hydroxyisolonchocarpin, papyriflavonol A, 3'-(3-methylbut-2-enyl)-3',4,7-trihydroxyflavane, kazinol A, kazinol B, broussoflavan A, kazinol F, and kazinol J have shown significant activity against CoV proteases [17].

The coronaviruses main protease plays an essential role in viral replication, including avian infectious bronchitis virus (IBV), transmissible gastrointestinal virus (TGEV), and murine hepatitis virus (MHV). It cleaves the polyproteins into smaller fragments and is considered an absolute requirement for replication [18]. In addition to the typical coronavirus structural proteins and replicase genes, COVID-19 has several currently unidentified nonstructural open reading frames in its genome [1]. Very recently, the crystal structure of the main protease of COVID19 in complex with a peptidomimetic inhibitor has been reported (Figure 1) [19] and makes it possible to investigate the interaction between 
the compounds and this protein as a target. In this study, we aim to run a high throughput virtual screening (HTVS) protocol for identifying compounds with potential inhibition against COVID-19 main protease. The selected compounds for HTVS were all natural products-derived.

\section{Methods}

\subsection{Protein preparation}

COVID-19 main protease crystal structure in complex with inhibitor N3 was downloaded from the RCSB Protein data bank (PDB ID: 6LU7). The structure of this protein was prepared by removing waters and minimization of the structure was carried out by using the protein preparation wizard in the Maestro suite (version 11.8, 2018). Hydrogen atoms were added, disulfide bonds were created, and water molecules beyond 3.00 $\AA$ from HET groups were deleted. Missing loops and side chains were filled in using prime. HET states were generated using Epik, protonated states were recognized utilizing PROPKA in pH 7.00 and the other changes were applied by default of software. Eventually, the COVID-19 main protease structure was optimized and minimized using the OPLS3 force field.

\subsection{Ligand preparation}

Four natural compound databases, including IBScreenNP database (https://www.ibscreen.com/naturalcompounds), the AnalytiCon Discovery database (https://www.ac-discovery.com), SpecNatural database (https://www.specs.net), as well as Zinc15 database

(http://www.zinc.docking.org/browse/catalogs/naturalproducts) were used to download more than ( 110.000) required natural products and molecules. Entire the downloaded compounds were prepared to utilize the LigPrep tool of Maestro 11.8 suite. The OPLS3 force field applied to convert 2D into 3D structures and reduce computational errors. Ionization states were applied using Epik at pH 7.00, and at most, four isomers per each ligand were generated.

\subsection{Grid generation and molecular docking}

Receptor grid generation of maestro suite was used to create the active binding site of the protease structure around the residues such as (Glu166, Phe140, His164, Gly143, Cys145, and Ala2). Site map module of maestro Schrödinger suite was applied to validate the grid box which was generated at (X: -12.06, Y: 13.95, Z: 69.49) and diameter midpoint box of $(X, Y, Z: 10 \AA)$, site maps with site score > 1.00 were more valid than the others.

The ligand docking was performed using Glide of Maestro suite in two precision steps, a large number of ligands were screened quickly employing high throughput virtual screening (HTVS), followed by extra precision (XP) method which was used to dock the best $10 \%$ of poses with excess precision. Flexible ligand sampling was applied to both protocols and the output result was expressed as a docking score.

\subsection{Induced-fit docking (IFD)}

Induced-fit docking (IFD) protocol was used for accurately redocking of selected compounds in a relaxed residue binding pocket. Standard and OPLS3e were employed as a protocol and force fields, respectively. The receptor grid was centered on the inhibitor N3 co-crystallized ligand around the residues such as Leu4, Asn142, and Cys145. Different conformers of ligands were analyzed at $2.5 \mathrm{Kcal} / \mathrm{mol}$ energy window and redocking glide was done with extra precision (XP). Eventually, the IFD score was explained in terms of kcal/mol.

\subsection{Free binding energy calculation}

Ligand-protein complex free binding energy was calculated using the different equations; molecular mechanics generalized born surface area (MM-GBSA) and molecular mechanics Poisson-Boltzmann surface area (MM-PBSA). Prime MM-GBSA module of maestro was utilized to calculate the free energy binding of the references and hit docking poses. The OPLS3e force field and VSGB refinement solvation model were chosen to predict the free binding energy of complexes.

$\Delta \mathrm{G}_{\text {binding }}=\mathrm{E}_{\text {complex }}($ minimized $)-\mathrm{E}_{\text {ligand }}($ minimized $)-\mathrm{E}_{\text {receptor }}($ minimized $)$

\subsection{Drug-like properties}


QikProp application was used for prediction of pharmacokinetics, ADME properties (Absorption, Distribution, Metabolism, and Excretion) and evaluating Drug-likeness features of all compounds. The selection of hit compounds was carried out by applying the Lipinski rule of five (RO5), polar surface area (PSA), central nervous system (CNS) activity, and percent oral absorption.

\section{Results}

In this study, discovering novel inhibitors for the coronavirus main protease (PDB ID: 6lu7) was investigated using molecular modeling. Glide high throughput virtual screening (HTVS) and extra precision (XP) of Schrödinger maestro suite (version 11.8, 2018) was used to virtual screening and molecular docking validation, respectively. The induced-fit docking (IFD) was selected to consider the flexibility of amino acid residues on the active binding site and avoiding false-positive data of the docking process.

Figure 2 demonstrated the method used for molecular docking of the selected compounds. Five steps were used for virtual screening and filtering hit structures out of 183388 compounds. In the first step, the HTVS docking workflow was employed to the fast selection of the entire compounds based on the affinity to the target protein. The results showed 4581 compounds have a good association with docking scores ranged $(-8.636$ to $-3.337 \mathrm{Kcal} / \mathrm{mol})$. These structures were selected for extra precision (XP) docking method which can evaluate the affinity of the compounds to bind to the protein target precisely. By applying this method, the number of remaining compounds was filtered to 174 compounds.

The IFD protocol has been reported to be an accurate method to consider both ligand and receptor flexibility. All 174 compounds were selected for docking using IFD protocol. By this method, 36 compounds were selected (Table S1). The final selection was made based on the data obtained from ADME properties, Lipinski rule of five, bioavailability and rescoring by MM/GBSA. The nineteen structures were selected and represented in Figure 3. This step resulted in 19 hit compounds out of 36 compounds while docking, pharmacokinetic properties, and MM/GBSA results of hit compounds are shown in Table 1. Interactions between the active compounds and the main protease were shown in Figure 5 and 6. Among all compounds, compound NP-20 (ZINC08765174) (an alkaloid) possessed the best docking score of -11.488 $\mathrm{Kcal} / \mathrm{mol}$ due to hydrogen bond and $\pi-\pi$ stacking interactions of Gly143, Cys145, Glu146, Hie41 (Figure 4), and Glide score - $11.488 \mathrm{kcal} / \mathrm{mol}$, and IFD scores $-673.42 \mathrm{kcal} / \mathrm{mol}$ against the protease. This compound was also the most active one among the entire present compounds in the databases.

\section{Discussion}

\subsection{Molecular docking}

The nineteen structures were selected by docking sudies and represented in Figure 3. The compounds belonged to the different classes of natural products such as alkaloids (NP-19, NP-4, NP-15, NP-20), flavonoids (NP-5, NP-7, NP-9, NP-3), quinones (NP-6, NP-10), coumarins (NP12, NP-13, NP-18), and some other natural products-derived.

Among alkaloids, compound NP-20 (ZINC08765174) possessed the best docking score of $-11.488 \mathrm{Kcal} / \mathrm{mol}$ due to hydrogen bond and $\pi-\pi$ stacking interactions of Gly143, Cys145, Glu146, Hie41 (Figure 4), and Glide score - $11.488 \mathrm{kcal} / \mathrm{mol}$, and IFD scores $-673.42 \mathrm{kcal} / \mathrm{mol}$ against the protease. This compound was also the most active one among the entire present compounds in the databases. Free binding energy was calculated for the best docking score results by MM/GBSA. The free binding energy of NP-4 was the lowest $(-46.14 \mathrm{kcal} / \mathrm{mol})$ in this class of natural products.

As mentioned before, some flavonoids have been identified as inhibitors of the coronavirus; four of them were shown in Figure 3. Among the flavonoids, NP-3 (ZINC96114284) was the best inhibitor of the main protease with docking score of $-10.743 \mathrm{Kcal} / \mathrm{mol}$. This ligand interacted with the active sites of the main protease, including Cys145, Gly143, and Thr190 through hydrogen bond interactions with the docking score value of $-10.743 \mathrm{Kcal} / \mathrm{mol}$, Glide score of $-10.752 \mathrm{Kcal} / \mathrm{mol}$, and IFD score of $-669.73 \mathrm{Kcal} / \mathrm{mol}$. The free binding energy of 3 compounds in this group was lower than $-36 \mathrm{Kcal} / \mathrm{mol}$.

Five compounds comprised quinone and coumarin skeletons out of the identified hit compounds. NP-6 (ZINC77257242) is an anthraquinone derivative which showed docking score of $-10.102 \mathrm{Kcal} / \mathrm{mol}$ due to hydrogen bond interactions of the ligand with Glu166, Gln $186, \mathrm{Gly} 143$, Cys 145, Thr26, and Hie26 amino acids. The Glide score and IFD score values of this ligand were -10.279 and $-666.89 \mathrm{Kcal} / \mathrm{mol}$, respectively. The compound NP-10 (ZINC77257242) possessed the lowest free binding energy of $-66.04 \mathrm{Kcal} / \mathrm{mol}$ and the amount of the free binding energy for other compounds in this class was lower than $-36 \mathrm{Kcal} / \mathrm{mol}$.

Some other natural products-derived have been identified as hit compounds. The compound NP-1 (ZINC03839114) was showing hydrogen bond interactions with GIn189, Glu166, His163, Leu141, and Cys145 amino acids with the docking score of $-11.132 \mathrm{Kcal} / \mathrm{mol}$, Glide score of

Page $4 / 13$ 
$-11.132 \mathrm{Kcal} / \mathrm{mol}$, and IFD score of $-674.28 \mathrm{Kcal} / \mathrm{mol}$. The free binding energy was calculated for these compounds and it was lower than -36 $\mathrm{Kcal} / \mathrm{mol}$ for all of the ligands in this class. The free binding energy of the compound NP-2 (ZINC03841676) was the lowest (-53.07 $\mathrm{Kcal} / \mathrm{mol})$.

Among the entire compounds, the free binding energy of 7compounds, NP-1, NP-2, NP-4, NP-8, NP-10, NP-11, and NP-16 showed lower amounts than the others. The free binding energy of the compound NP-10 (ZINC06092274) was the lowest (-66.04 Kcal/mol). Eventually, 21 compounds showed free binding energy of lower than $-36 \mathrm{Kcal} / \mathrm{mol}$. The results of molecular docking and ligand-protein interaction for the references such as peramivir, laninamivir, and hydroxychloroquine were introduced in Figure 7.

\subsection{Absorption, Distribution, Metabolism, and Excretion (ADME)}

Drug likeness of 36 natural products (data of all 36 compounds have been listed in supplementary Table 1) was predicted by the QikProp panel of Schrödinger maestro suite. Lipinski's rule of five was used to test the bioavailability characteristics (ADME) of these compounds. According to the rule, molecules with Molecular Weight $\leq 500$, hydrogen bond donors $\leq 5$ and acceptors $\leq 10$, calculated octanol-water partition coefficient, and log $\mathrm{P} \leq 5$ possess good membrane permeability [20]. In this study, these properties for the lead compounds were estimated.

All compounds possess at least one hydrogen bond donor and four hydrogen bond acceptors. For pharmacokinetic property, polar surface area (PSA), central nervous system (CNS) activity, and percent oral absorption were predicted. Results of in silico pharmacokinetic study on these natural products showed good pharmacokinetic properties.

The hydrophilicity of all compounds was determined by calculating the log P-value. It has been suggested that the log P value must be less than five, and high log P results in poor absorption. According to this study, the partition coefficient (QPlog Po/w) was within the permissible range for the selected natural products. Calculated PSA was within the range of 7.0-200.0 $\AA$. CNS activity of these natural products was evaluated. According to the results, all the selected natural products were classified as CNS-inactive compounds.

The human oral absorption percentage of 19 compounds was in the appropriate range of 81 to $100 \%$. Compounds NP-2, NP-5, NP-8, NP-11, NP-13, NP-18, and NP-20 showed $100 \%$ oral absorption. Also, entire hit compounds showed over $50 \%$ oral absorption. It can be observed in

Table 1 that no violations of Lipinski's rule (polar surface area, molecular weight, number of hydrogen donors and acceptors) were found for hit compounds and all mentioned properties were within the allowed range, thereby indicating their potential as a drug-like molecule.

Aqueous solubility (logS) has ever been one of the most significant factors in the brain/blood partition coefficient and percent human oral absorption. Compounds distribution of HTVS results are based on the relations between brain/blood, octanol/water partition coefficient, aqueous solubility, and percent absorption were represented in Figure 8. Approximately, 99\% of HTVS results possessed predicted QPlogBB permissible range (-3 to 1.2), $70 \%$ of compounds had up to $80 \%$ human oral absorption and about $99 \%$ were within the considered range of predicted QPlogPo/w (-2 to 5). Increasing in the QPlogPo/w values of the compounds causes increasing in the absorption percentage. Also, direct relations between QPlogPo/w, QPlogBB, and absorption percentge, and opposite relation between QPlogPo/w and QPlogScan be seen.

\section{Conclusion}

Nineteen compounds, NP-1 to NP-19 were selected and proposed as potential inhibitors for the main protease of 2019-nCoV by considering $A D M E$ and free binding energy values which were greater than the reference compounds. The docking score of selected compounds were between -8.049 to $-11.132 \mathrm{Kcal} / \mathrm{mol}$ and all the selected compounds had PSA, acceptor and donor hydrogen bonds, molecular weights, as well as partition coefficient amounts in the range. Eventually, the free binding energies of the screened compounds were lower than -35 $\mathrm{Kcal} / \mathrm{mol}$. The antimicrobial activity of some selected compounds such as Lonchocarpol A [21] and catechin [22] have been reported. Alkaloid derivatives, especially aporphines and isoboldine have shown antibacterial activity and potent activity against $\mathrm{S}$. aureus and E. coli, respectively [23].

\section{Abbreviations}

CoVs: Coronaviruses

2019-nCoV: 2019 novel coronavirus

HTVS: High Throughput Virtual Screening

XP: Extra precision

Page 5/13 
IFD: induced-fit docking

WHO: Health Organization

UTR: Untranslated region

SARS:Severe Acute Respiratory Syndrome

MERS: Middle East Respiratory Syndrome

IBV: Infectious bronchitis virus

TGEV: Transmissible gastrointestinal virus

MHV: Murine hepatitis virus

RCSB: Research collaborator for structural bioinformatics

PDB: Protein data bank

OPLS: Optimized potentials for liquid simulations

MM-GBSA: Molecular mechanics generalized born surface area

MM-PBSA: Molecular mechanics Poisson-Boltzmann surface area

ADME: Absorption, Distribution, Metabolism, and Excretion

R05: Rule of five

PSA: Polar surface area

CNS: Central nervous system

VSGB: Variable-dielectric generalized Born

QPlogBB: Predicted brain/blood partition coefficient

QPlogPo/w: Predicted octanol/water partition coefficient

\section{Declarations}

\section{Ethics approval and consent to participate}

Not Applicable.

\section{Consent for publication}

Not Applicable.

\section{Availability of data and materials}

The datasets used and/or analyzed during the current study are available from the corresponding author on reasonable request.

\section{Competing of interest}

The authors declare that there is no competing interest.

\section{Funding}

Not Applicable

Authors' contributions 
$\mathrm{MO}$ and MB performed the majority of the experiments and wrote the manuscript and contributed equally to this work. PM and SNE planned and guided the research and supported to write this manuscript. All authors read and revised the manuscript and approved the final manuscript.

\section{Acknowledgements}

Not Applicable.

\section{References}

1. Zhu N, Zhang D, Wang W, Li X, Yang B, Song J, Zhao X, Huang B, Shi W, Lu R. A novel coronavirus from patients with pneumonia in China, 2019. N Engl J Med. 2020.

2. WHO. Situation Report-88. April 17th 2020.

3. Su S, Wong G, Shi W, Liu J, Lai AC, Zhou J, Liu W, Bi Y, Gao GF. Epidemiology, genetic recombination, and pathogenesis of coronaviruses. Trends Microbiol. 2016;24(6):490-502.

4. Lo CY, Tsai TL, Lin CN, Lin CH, Wu HY. Interaction of coronavirus nucleocapsid protein with the 5 '-and 3 '-ends of the coronavirus genome is involved in genome circularization and negative-strand RNA synthesis. FEBS J. 2019;286(16):3222-39.

5. Peiris J, Lai S, Poon L, Guan Y, Yam L, Lim W, Nicholls J, Yee W, Yan W, Cheung M. Coronavirus as a possible cause of severe acute respiratory syndrome. Lancet. 2003;361(9366):1319-25.

6. Raj VS, Osterhaus AD, Fouchier RA, Haagmans BL. MERS: emergence of a novel human coronavirus. Curr Opin Virol. 2014;5:58-62.

7. Wu F, Zhao S, Yu B, Chen Y-M, Wang W, Song Z-G, Hu Y, Tao Z-W, Tian J-H, Pei Y-Y. A new coronavirus associated with human respiratory disease in China. Nature. 2020;579(7798):265-9.

8. Contini A. Virtual screening of an FDA approved drugs database on two COVID-19 coronavirus proteins. 2020.

9. Ryu YB, Jeong HJ, Kim JH, Kim YM, Park J-Y, Kim D, Naguyen TTH, Park S-J, Chang JS, Park KH. Biflavonoids from Torreya nucifera displaying SARS-CoV 3CLpro inhibition. Bioorg Med Chem. 2010;18(22):7940-7.

10. Lau K-M, Lee K-M, Koon C-M, Cheung CS-F, Lau C-P, Ho H-M, Lee MY-H, Au SW-N, Cheng CH-K, Bik-San Lau C. Immunomodulatory and anti-SARS activities of Houttuynia cordata. J Ethnopharmacol. 2008;118(1):79-85.

11. Recio MdC, Just MJ, Giner RM, Mañez S, Rios JL, Hostettmann K. Anti-inflammatory activity of saikosaponins from Heteromorpha trifoliata. J Nat Prod. 1995;58(1):140-4.

12. Cheng PW, Ng LT, Chiang LC, Lin CC. Antiviral effects of saikosaponins on human coronavirus 229E in vitro. Clin Exp Pharmacol Physiol. 2006;33(7):612-6.

13. Wollenweber E. Flavones and flavonols. The Flavonoids Advances in Research Since 1986: Routledge; 2017. p. 259-335.

14. Molisch H, Goldschmiedt G. über das Scutellarin, einen neuen Körper bei Scutellaria und anderen Labiaten: K. k. Hof-und Staatsdr.; 1901.

15. Hertog MG, Feskens EJ, Kromhout D, Hollman P, Katan M. Dietary antioxidant flavonoids and risk of coronary heart disease: the Zutphen Elderly Study. Lancet. 1993;342(8878):1007-11.

16. Yu M-S, Lee J, Lee JM, Kim Y, Chin Y-W, Jee J-G, Keum Y-S, Jeong Y-J. Identification of myricetin and scutellarein as novel chemical inhibitors of the SARS coronavirus helicase, nsP13. Bioorg Med Chem Lett. 2012;22(12):4049-54.

17. Park J-Y, Yuk HJ, Ryu HW, Lim SH, Kim KS, Park KH, Ryu YB, Lee WS. Evaluation of polyphenols from Broussonetia papyrifera as coronavirus protease inhibitors. J Enzyme Inhib Med Chem. 2017;32(1):504-12.

18. Lai L, Han X, Chen H, Wei P, Huang C, Liu S, Fan K, Zhou L, Liu Z, Pei J. Quaternary structure, substrate selectivity and inhibitor design for SARS 3C-like proteinase. Curr Pharm Des. 2006;12(35):4555-64.

19. Liu X, Zhang B, Jin Z, Yang H, Rao Z. The crystal structure of COVID-19 main protease in complex with an inhibitor N3. 2020.

20. Proudfoot JR. Drugs, leads, and drug-likeness: an analysis of some recently launched drugs. Bioorg Med Chem Lett. 2002;12(12):164750.

21. Salvatore MJ, King AB, Graham AC, Onishi HR, Bartizal KF, Abruzzo GK, Gill CJ, Ramjit HG, Pitzenberger SM, Witherup KM. Antibacterial activity of Lonchocarpol A. J Nat Prod. 1998;61(5):640-2.

22. Bais HP, Walker TS, Stermitz FR, Hufbauer RA, Vivanco JM. Enantiomeric-dependent phytotoxic and antimicrobial activity of ( \pm )-catechin. A rhizosecreted racemic mixture from spotted knapweed. Plant Physiol. 2002;128(4):1173-9.

23. Abbasoglu U, Sener B, Günay Y, Temizer H. Antimicrobial activity of some isoquinoline alkaloids. Arch Pharm. 1991;324(6):379-80.

\section{Tables}

Page $7 / 13$ 
Table 1. Representing Glide docking and IFD scores ( $\mathrm{kcal} / \mathrm{mol})$, with ADME screening results

\begin{tabular}{|c|c|c|c|c|c|c|c|c|c|c|c|c|}
\hline No. & Compound & $\begin{array}{l}\text { docking } \\
\text { score }\end{array}$ & $\begin{array}{l}\text { glide } \\
\text { gscore }\end{array}$ & $\begin{array}{l}\text { IFD } \\
\text { Score }\end{array}$ & $\Delta \mathrm{G}_{\text {bind }}$ & PSA & MW & $\begin{array}{l}\text { Donor } \\
\text { HB }\end{array}$ & $\begin{array}{l}\text { Accpt } \\
\text { HB }\end{array}$ & $\begin{array}{l}\text { QPLog } \\
\text { Po/w }\end{array}$ & $\begin{array}{l}\text { \%Oral } \\
\text { abs. }\end{array}$ & CNS \\
\hline $\begin{array}{l}\text { NP- } \\
1\end{array}$ & ZINC03839114 & -11.132 & -11.132 & -674.28 & -51.9 & 149.6 & 462.455 & 3 & 9.5 & 1.032 & 64.756 & -2 \\
\hline $\begin{array}{l}\text { NP- } \\
2\end{array}$ & ZINC03841676 & -11.068 & -11.072 & -673.56 & -53.07 & 71.2 & 394.513 & 2 & 6.45 & 3.854 & 100 & -1 \\
\hline $\begin{array}{l}\text { NP- } \\
3\end{array}$ & ZINC96114284 & -10.743 & -10.752 & -669.73 & -37.3 & 131.4 & 404.378 & 1 & 7 & 2.537 & 75.723 & -2 \\
\hline $\begin{array}{l}\text { NP- } \\
4\end{array}$ & ZINC98364422 & -10.315 & -10.317 & -669.05 & -46.14 & 104.2 & 384.393 & 1 & 10 & 1.917 & 87.351 & -1 \\
\hline $\begin{array}{l}\text { NP- } \\
5\end{array}$ & Lonchocarpol A & -10.234 & -10.234 & -670.01 & -39.96 & 91.7 & 408.493 & 2 & 4 & 4.845 & 100 & -2 \\
\hline $\begin{array}{l}\text { NP- } \\
6\end{array}$ & ZINC77257242 & -10.102 & -10.279 & -666.89 & -36.9 & 143.2 & 316.267 & 2 & 6.7 & 0.552 & 58.759 & -2 \\
\hline $\begin{array}{l}\text { NP- } \\
7\end{array}$ & Norkurarinone & -9.91 & -9.91 & -670.69 & -18.92 & 113.5 & 424.493 & 3 & 4.75 & 4.199 & 90.687 & -2 \\
\hline $\begin{array}{l}\text { NP- } \\
8\end{array}$ & ZINC72321780 & -9.516 & -9.516 & -669.24 & -47.65 & 96.3 & 423.388 & 3 & 7.4 & 3.736 & 100 & -1 \\
\hline $\begin{array}{l}\text { NP- } \\
9\end{array}$ & $(-)$-Catechin & -9.444 & -9.444 & -668.69 & -37.36 & 116.8 & 290.272 & 5 & 5.45 & 0.448 & 59.967 & -2 \\
\hline $\begin{array}{l}\text { NP- } \\
10\end{array}$ & Altertoxin I & -9.429 & -9.429 & -664.92 & -66.04 & 133.3 & 352.343 & 2 & 5.95 & 1.369 & 66.233 & -2 \\
\hline $\begin{array}{l}\text { NP- } \\
11\end{array}$ & ZINC72321775 & -9.356 & -9.356 & -668.71 & -47.28 & 75.9 & 379.378 & 3 & 5.9 & 3.527 & 100 & -1 \\
\hline $\begin{array}{l}\text { NP- } \\
12\end{array}$ & ZINC35458935 & -9.309 & -9.349 & -667.36 & -42.9 & 148.8 & 428.395 & 3 & 7.65 & 1.891 & 72.908 & -2 \\
\hline $\begin{array}{l}\text { NP- } \\
13\end{array}$ & ZINC00719192 & -9.285 & -9.285 & -667.72 & -38.45 & 114.5 & 482.415 & 1 & 7.25 & 4.416 & 100 & -1 \\
\hline $\begin{array}{l}\text { NP- } \\
14\end{array}$ & ZINC72321774 & -9.22 & -9.22 & -667.92 & -40.03 & 89.2 & 395.378 & 3 & 6.65 & 2.982 & 89.497 & -1 \\
\hline $\begin{array}{l}\text { NP- } \\
15\end{array}$ & ZINC31158868 & -9.114 & -9.115 & -668.84 & -41.22 & 121.9 & 291.303 & 3 & 7.7 & 1.073 & 56.981 & -2 \\
\hline $\begin{array}{l}\text { NP- } \\
16\end{array}$ & ZINC09033965 & -9.069 & -9.069 & -669.16 & -46.67 & 99.7 & 433.233 & 1 & 8.5 & 1.621 & 81.002 & -1 \\
\hline $\begin{array}{l}\text { NP- } \\
17\end{array}$ & ZINC02109515 & -8.702 & -8.86 & -669.36 & -41.79 & 75.5 & 360.335 & 3 & 3.5 & 1.854 & 65.671 & -1 \\
\hline $\begin{array}{l}\text { NP- } \\
18\end{array}$ & ZINC15120609 & -8.243 & -8.243 & -667.9 & -37.92 & 95.5 & 372.417 & 2 & 6.2 & 3.482 & 100 & -2 \\
\hline $\begin{array}{l}\text { NP- } \\
19\end{array}$ & Isoboldine & -8.049 & -8.049 & -667.29 & -45.22 & 113.5 & 424.493 & 3 & 4.75 & 4.199 & 90.687 & -2 \\
\hline $\begin{array}{l}\text { NP- } \\
20\end{array}$ & ZINC08765174 & -11.5 & -11.5 & -673.4 & -27.5 & 74.1 & 431.6 & 2 & 5.5 & 4.8 & 100 & -1 \\
\hline $\begin{array}{l}\text { NP- } \\
21\end{array}$ & Peramivir & -9.763 & -9.763 & -670.26 & -39.74 & 113.5 & 424.493 & 3 & 4.75 & 4.199 & 90.687 & -2 \\
\hline $\begin{array}{l}\text { NP- } \\
22\end{array}$ & Laninamivir & -8.513 & -8.513 & -671.07 & -33.73 & 113.5 & 424.493 & 3 & 4.75 & 4.199 & 90.687 & -2 \\
\hline $\begin{array}{l}\text { NP- } \\
23\end{array}$ & Hydroxychloroquine & -7.407 & -7.407 & -669.57 & -39.41 & 113.5 & 424.493 & 3 & 4.75 & 4.199 & 90.687 & -2 \\
\hline $\begin{array}{l}\text { NP- } \\
24\end{array}$ & Baloxavir marboxil & -7.194 & -7.194 & -663.34 & -40.53 & 113.5 & 424.493 & 3 & 4.75 & 4.199 & 90.687 & -2 \\
\hline
\end{tabular}


Figures

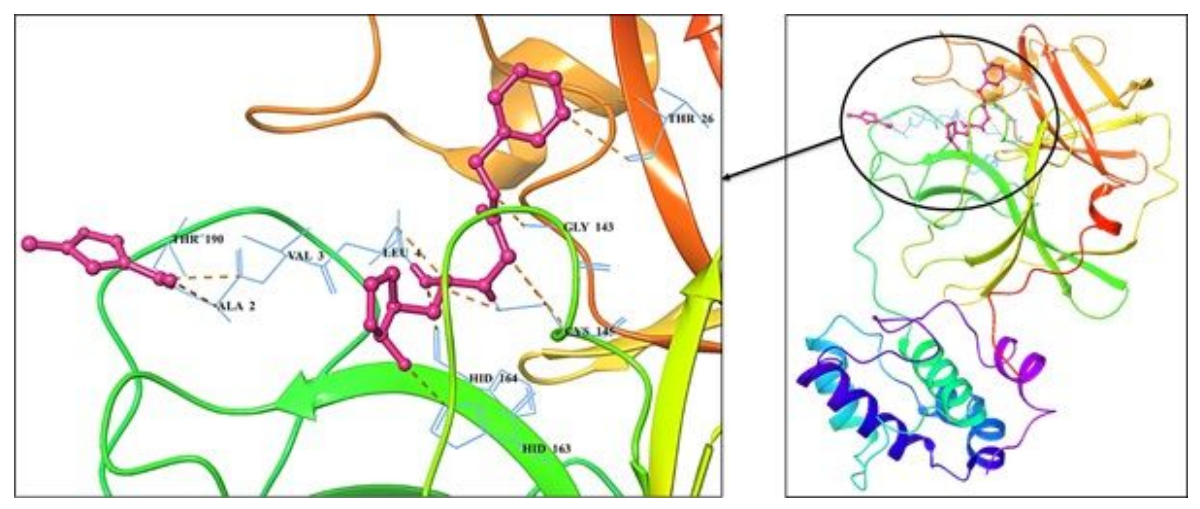

Figure 1

The 3D representation of N3 co-crystallized interaction on coronavirus main protease (PDB ID: 6LU7)

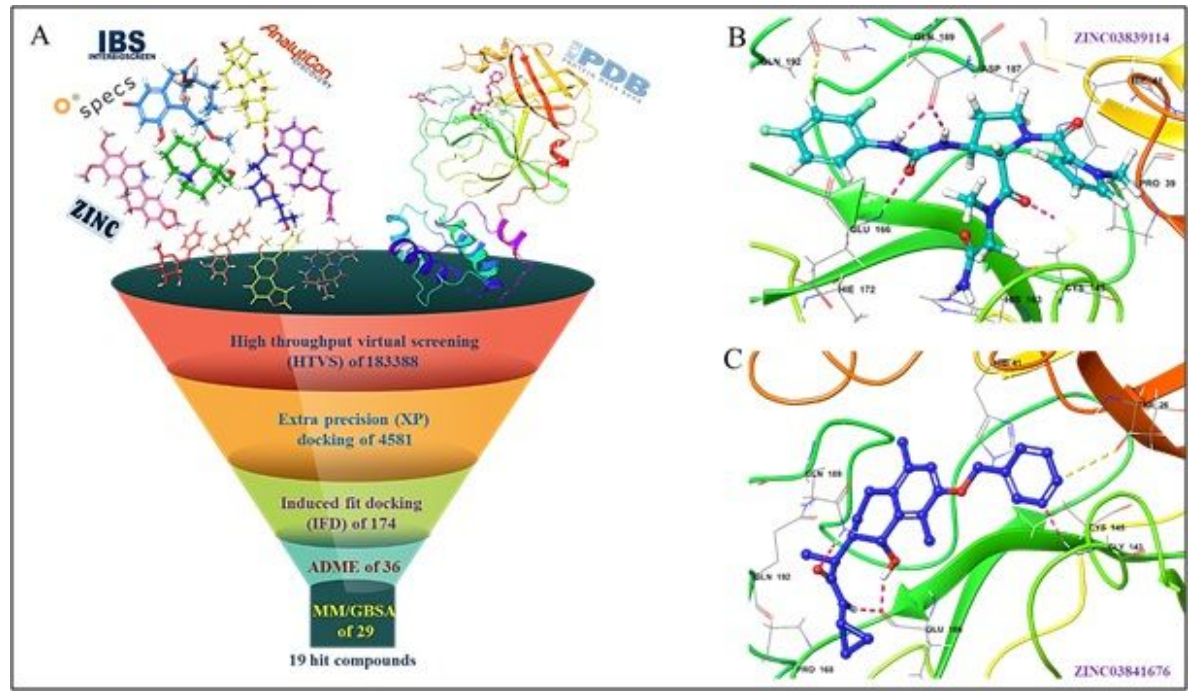

\section{Figure 2}

A) Flowchart of computational analysis for identifying novel inhibitors for coronavirus as the primary protease inhibitors. B and C) Interaction of the best IFD results. 
Alkaloids<smiles>CC(CCc1ccccc1)NC(=O)C1CCCN(C(=O)CCc2c[nH]c3ccccc23)C1</smiles><smiles>COc1cc2c3c(ccc(O)c3c1)CCN(C)CC2</smiles><smiles>CC(O)C=CC(CC(=O)O)Nc1ccc(C(=O)O)cc1</smiles><smiles>O=C1c2ccccc2N(C(=O)c2ccccc2)C(=O)CN1c1ccccc1</smiles>

NP-20

NP-19

NP-15

NP-4<smiles>CC(C)=CCc1c(O)c(CC=C(C)C)c2c(c1O)C(=O)C[C@@H](c1ccc(O)cc1)O2</smiles><smiles>CCC(Cc1oc(-c2ccc(O)cc2Cl)cc(=O)c1O)CC(C)C</smiles><smiles>Cc1ccc(C2Cc3c(O)cc(O)cc3OC2c2ccccc2)cc1</smiles>

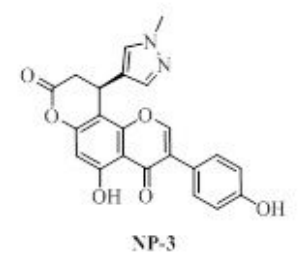

Quinones and coumarins<smiles>COCc1c(O)cc2c(c1O)C(=O)c1c(O)cc(O)cc1C2=O</smiles>

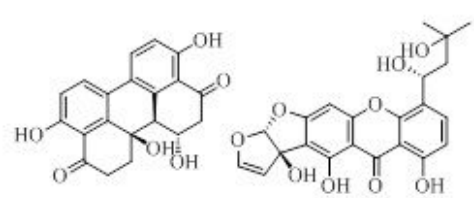

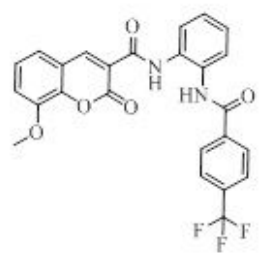

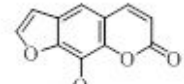

NP-6

NP-10

NP-12

NP-13

NP-18

Natural product derived

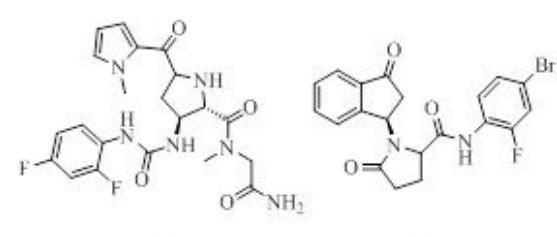

NP-1

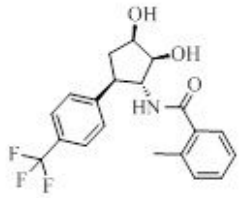

NP-11<smiles>O=C(O)C1Cc2ccccc2NC1c1ccc(C(F)(F)F)cc1</smiles>

NP-17<smiles>O=C(CNC1C(O)C[C@@H](O)CC1c1ccc(C(F)(F)F)cc1)Oc1ccccc1</smiles>

NP-14<smiles>O=C(NC1C(O)CC(O)CC1c1ccc(C(F)(F)F)cc1)c1ccc2c(c1)OCCO2</smiles>

NP-8

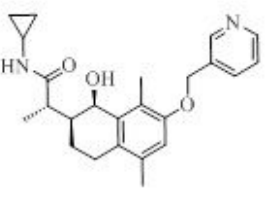

$N P-2$

Figure 3

The structure of compounds which showed the best docking scores

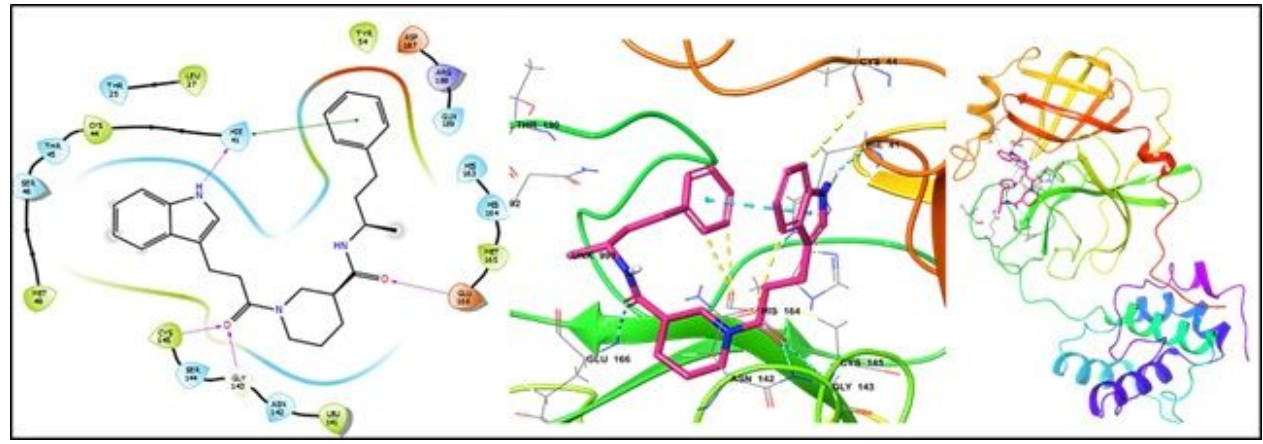

Figure 4

ligand-protein interactions of the compound NP-20 (ZINC08765174), including Gly143, Cys145, Glu146, Hie41 hydrogen bond and $\pi-\pi$ stacking interactions. 


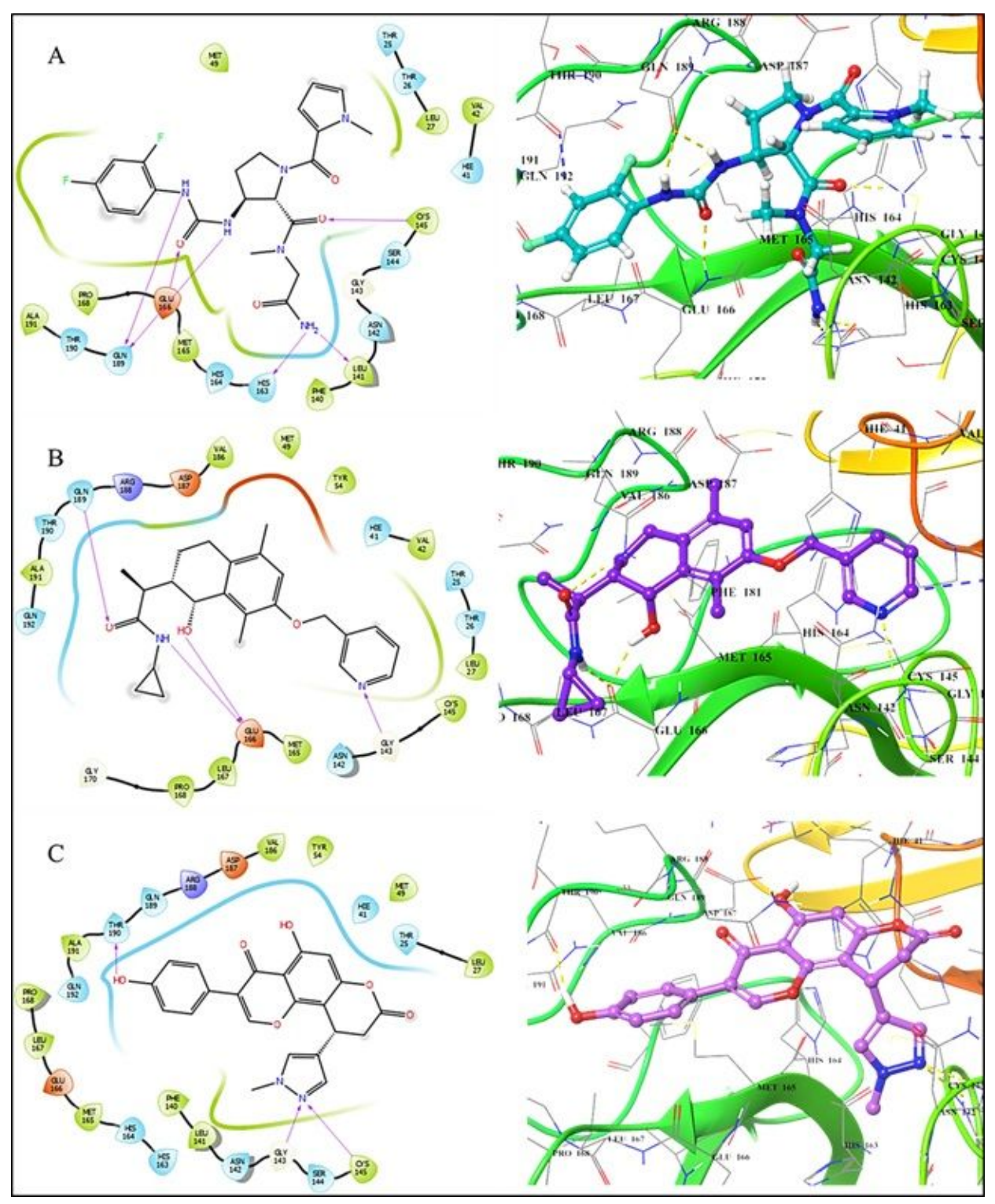

Figure 5

Ligand-protein interactions of hit compounds; A) NP-1 B) NP-2 C) NP-3 


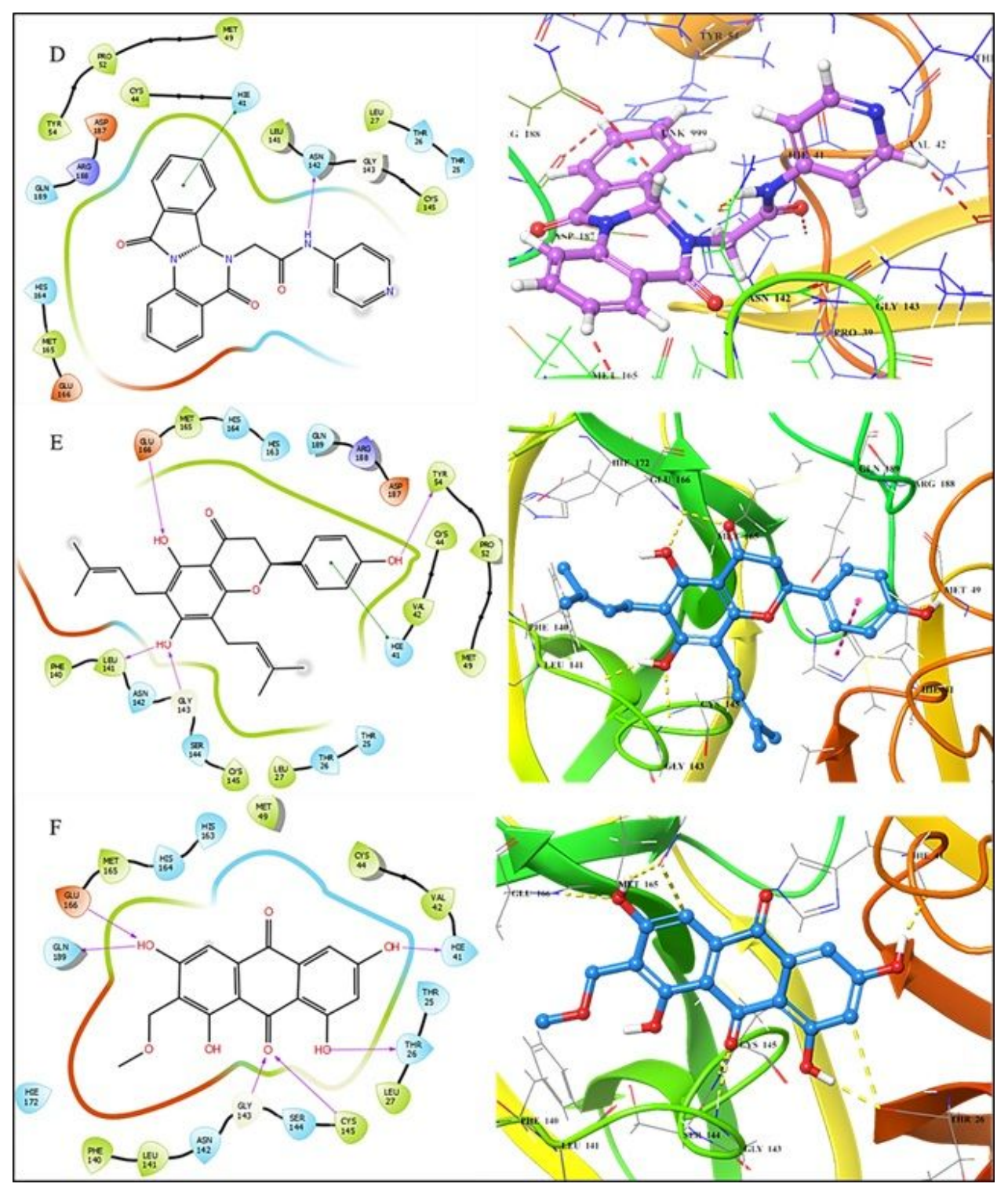

Figure 6

Ligand-protein interactions of hit compounds; D) NP-4 E) NP-5 F) NP-6

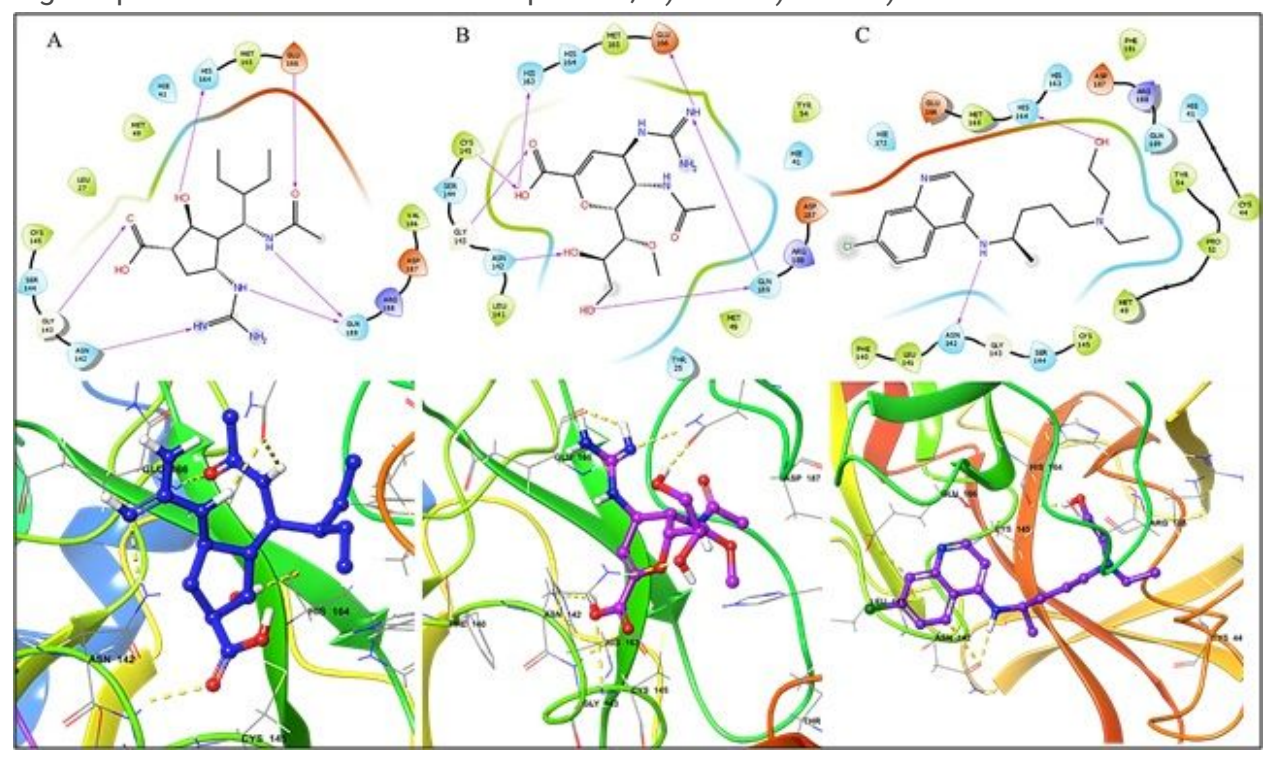

Figure 7 
The 2D and 3D ligand-protein interactions of reference compounds with amino acids residues: A) peramivir, Asn142, Cys145, GIn189 and 166, His164, and Hie41 B) laninamivir, Thr26, Asn142, Leu141, Gly 164, and Glu189 C) hydroxychloroquine, Gly143, and His164 hydrogen bond interaction.
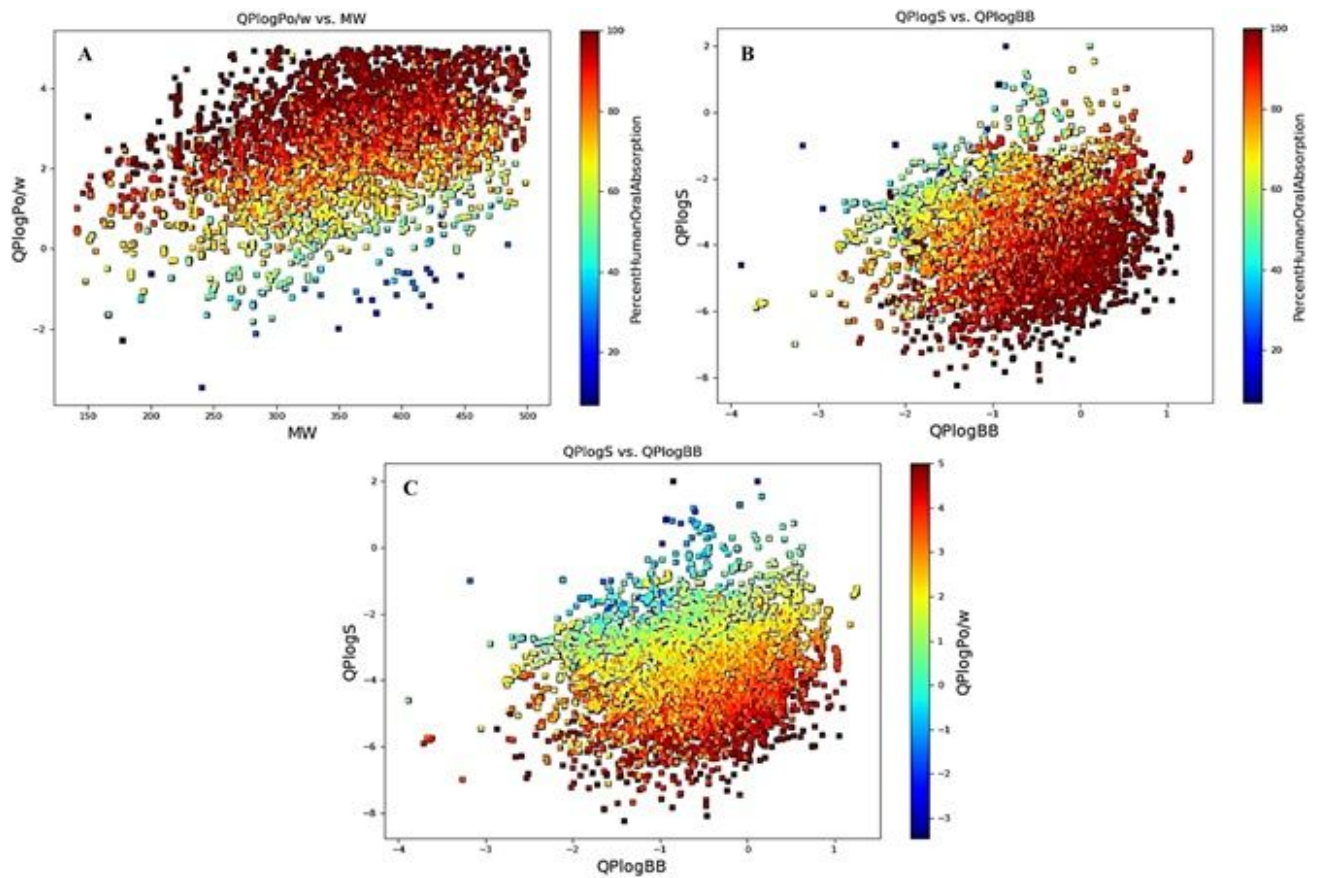

\section{Figure 8}

Plots of the compounds distribution of HTVS results. A) Compounds distribution of logPo/w vs. MW. B) Compounds distribution of logS vs. $\log B B$. The absorption percentage was colored for both plots. C) Compounds distribution of logS vs. logBB. The logPo/w was colored. I think the colors should be explained abit here.

\section{Supplementary Files}

This is a list of supplementary files associated with this preprint. Click to download.

- SUP.docx 